\title{
Clinical Features of Segmental Infantile Hemangioma: A Prospective Study
}

This article was published in the following Dove Press journal:

Therapeutics and Clinical Risk Management

\author{
Tong Qiu' \\ Kaiying Yang' \\ Shiyi Dai' \\ Siyuan Chen $^{2}$ \\ Yi Ji (iD)
}

'Division of Oncology, Department of Pediatric Surgery, West China Hospital of Sichuan University, Chengdu 61004I, People's Republic of China; ${ }^{2}$ Pediatric Intensive Care Unit, Department of Critical Care Medicine, West China Hospital of Sichuan University, Chengdu 6I004I, People's Republic of China

Correspondence: $Y \mathrm{i}$ Ji

Division of Oncology, Department of Pediatric Surgery, West China Hospital of Sichuan University, \#37\# Guo-Xue-Xiang, Chengdu 61004I, People's Republic of China

Fax +862885423453

Email jijiyuanyuan@I63.com
Background: Infantile hemangioma ( $\mathrm{IH})$ is the most common benign tumor in children. However, few studies have reported the clinical features of segmental IH. We aimed to determine the clinical characteristics of segmental IH and to identify features that may aid clinicians in managing segmental IH.

Methods: In the cross-sectional prospective study approved by the Ethics Committee of the hospital, children diagnosed with IH were recruited, and information including patient demographics, IH morphology and anatomical location, complications and treatments were recorded and analyzed.

Results: In total, 153 patients with segmental IH and 1375 patients with nonsegmental IH were enrolled in this study. The average age on the day of the first visit in patients with segmental IH was $3.63 \pm 3.23$ months. In 69 patients (45.10\%), segmental IH was diagnosed at birth. Most segmental IHs (49.67\%) occurred in the limbs, while only $22.04 \%$ of nonsegmental IHs occurred in the extremities $(P<0.001)$. Thirteen patients $(8.50 \%)$ with segmental IH had ulceration. Compared with patients with nonsegmental IHs, patients with segmental IHs were more likely to be treated with oral drugs $(P<0.001)$.

Conclusion: Segmental IHs mainly occur in the extremities and are frequently diagnosed at birth. Segmental IHs are usually accompanied by ulceration, which are more commonly seen in the neck and perineal/perianal/genital areas than nonsegmental IHs. Oral propranolol is prescribed more often in patients with segmental IH than in those with nonsegmental IH.

Keywords: segmental infantile hemangioma, clinical features, complications, treatment, ulceration

\section{Introduction}

Infantile hemangioma (IH) is the most common benign tumor in children, with an incidence of $4-5 \%$. IH is more common in females than in males. ${ }^{1}$ Most IHs are small and usually gradually subside without treatment; however, some special types of IHs need the attention of clinicians and standardized treatment. The latest clinical practice guidelines for the management of IH were established by the American Academy of Pediatrics (AAP) in 2019. The AAP guideline defines a hemangioma larger than $5 \mathrm{~cm}$ in diameter as segmental $\mathrm{IH}^{2}$ Segmental $\mathrm{IH}$ is a high-risk type of IH. It may be associated with serious complications, such as ulceration and airway involvement, ${ }^{3,4}$ and can also be accompanied by structural abnormalities. However, there are only a few large-sample studies reporting the clinical characteristics of segmental IHs. In addition, the differences in clinical features between segmental IH and nonsegmental IH have not been well explored. Therefore, we conducted a prospective cross-sectional study to investigate the clinical features of segmental 
$\mathrm{IH}$, with the aim of increasing the understanding of segmental $\mathrm{IH}$ and preventing morbidity.

\section{Patients and Methods}

The Infantile Hemangioma Research Group of West China Hospital of Sichuan University launched a prospective study on IH from October 2017 to August 2019. The study was approved by the Ethics Committee of West China Hospital of Sichuan University. All the researchers had been trained about the research program and on data collection. Written informed consent was obtained from all the patients' parents. The researchers registered samples of all IH patients who were treated at urgent care visits and in the inpatient or outpatient clinic of West China Hospital of Sichuan University. Information including patient sex, age at the first visit, date of $\mathrm{IH}$ onset, growth stage of $\mathrm{IH}$, type of $\mathrm{IH}$, anatomic location of $\mathrm{IH}$, complications, location of ulceration, and current treatment regimens was collected. The study has been registered at www.clinicaltrial.gov (NCT03331744). The posterior fossa, hemangioma, arterial lesions, cardiac abnormalities/aortic coarctation, and eye abnormalities (PHACE) syndrome and lower body hemangioma, urogenital abnormalities/ulceration, myelopathy, bony deformities, anorectal malformations/arterial anomalies, and rectal anomalies (LUMBAR) in children with segmental hemangioma will be further elaborated and explained in our follow-up study.
The inclusion criteria of this study were as follows: patients aged $0-1$ year with a diagnosis of IH. Patients were excluded if they had received any previous treatment, if they were diagnosed with congenital hemangioma or vascular malformation, or if some clinical information was unavailable. Hemangioma lesions were classified by soft-tissue depth as superficial, mixed or deep. Superficial IHs were measured vertically with a soft tape measure $\left(\mathrm{cm}^{2}\right)$, while mixed and deep IH types were measured by ultrasound. The longest diameter was considered the final value. For patients with multiple hemangioma lesions, detailed information was obtained for the most clinically important hemangioma (typically the largest or most ulcerated lesion). Segmental $\mathrm{IH}$ was defined as $\mathrm{IH}$ involving a broad anatomic region that often appeared plaque-like and measured more than $5 \mathrm{~cm}$ in diameter. ${ }^{2}$ According to this definition, IH patients were divided into the segmental IH group and the nonsegmental IH group. The differences between these two groups were analyzed. As for high-risk IHs defined by $\mathrm{AAP}^{2}$ or IHs treated with oral medication, we would follow up for at least 6 months for children with IH who were assessed as high-risk IHs or received oral drug therapy.

The data were calculated by IBM SPSS Statistics 25.0 software. The qualitative data of the two groups were analyzed by $X^{2}$ test or Fisher's exact test. The quantitative data were analyzed by Student's $t$-test. Differences were

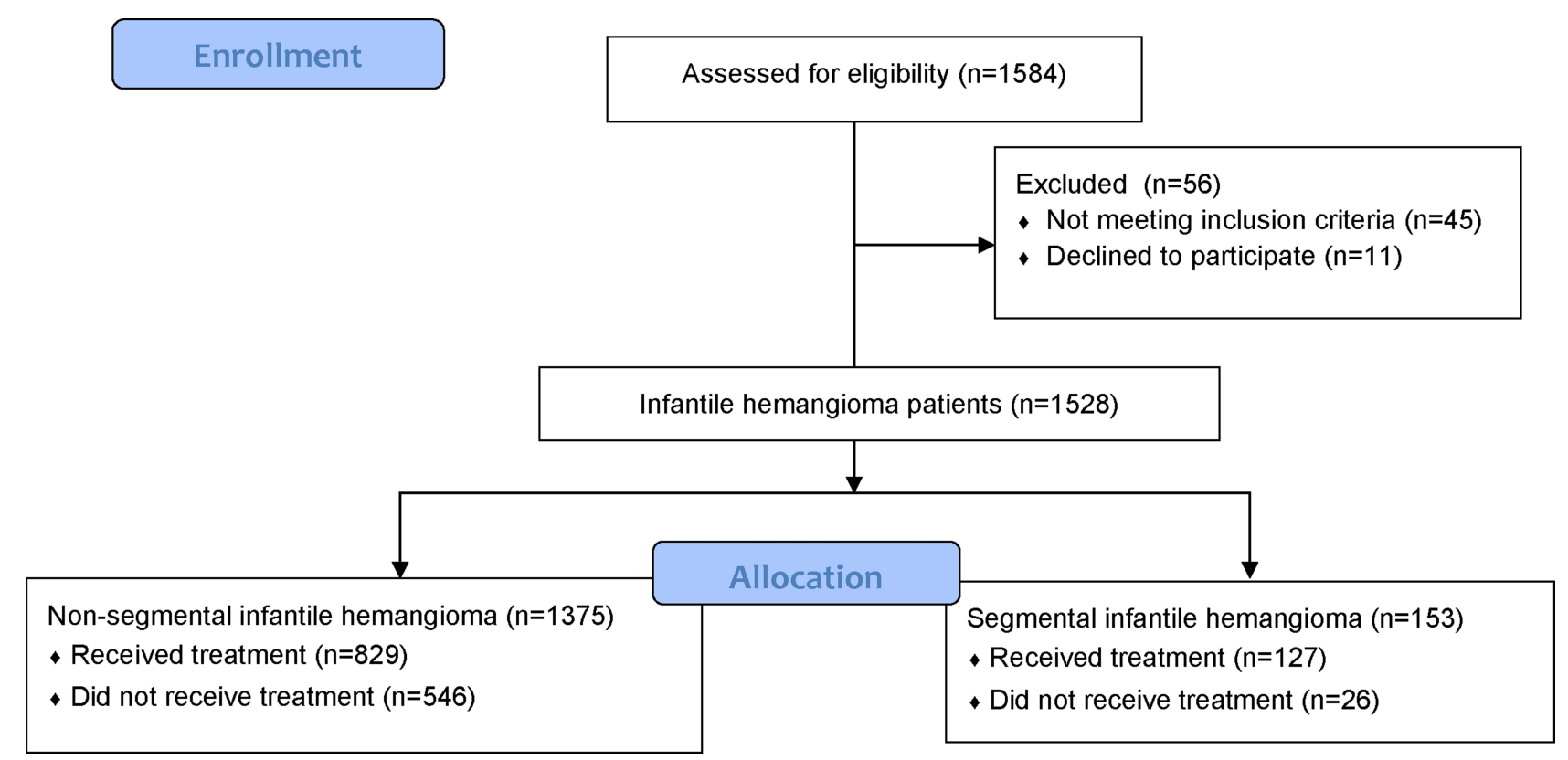

Figure I Study flowchart of allocation protocol for segmental IH and nonsegmental IH. 
considered statistically significant when the $P$ value was $<0.05$.

\section{Results}

\section{Patient Demographics}

A total of 1584 patients were screened for eligibility, and 1528 patients with $\mathrm{IH}$ met the criteria for inclusion and were ultimately enrolled in the study (Figure 1). There were 1375 patients with nonsegmental IH and 153 patients with segmental IH. There were no significant differences in the demographic characteristics between segmental $\mathrm{IH}$ and nonsegmental IH groups. The average age at the first visit in patients with nonsegmental $\mathrm{IH}$ and segmental $\mathrm{IH}$ was $3.41 \pm 2.73$ months and $3.63 \pm 3.23$ months, respectively (Table 1).

\section{IH Morphology and Anatomical Location}

Through a detailed questionnaire, we gathered information about the time when the IH was first noted. The presence of a hemangioma precursor at birth was more often noted in patients with segmental IH patients than in nonsegmental IH patients $(P<0.001)$ (Figure 2$)$. With regard to the subtypes of $\mathrm{IH}$, superficial $\mathrm{IH}$ occurred more frequently in the nonsegmental IH group $(P<0.001)$, while mixed $\mathrm{IH}$ occurred more frequently in the segmental IH group $(P<0.001)$. In $49.67 \%$ of the patients with segmental $\mathrm{IH}$, the lesions were located on the extremities, while only $22.04 \%$ of nonsegmental IHs were located on the extremities $(P<0.001)$. Nonsegmental IHs mainly occurred in the head and face area (Figure 3), while segmental IHs involving the head and face area (Figure 4) were less common (39.71\% vs $16.34 \%, P<0.001$ ) (Table 1 ).

\section{Complications}

Ulceration was the most common complication of IHs. We found that ulcerations occurred more frequently in segmental IHs than in nonsegmental IHs $(8.50 \%$ vs $4.07 \%$, $P=0.012$ ). Segmental neck and perineal $/$ perianal $/$ genital IHs were more likely to develop ulcers than nonsegmental IHs (Table 2). In addition, segmental IHs were more likely to cause airway obstruction than nonsegmental IHs $(P<0.001)$. Five cases $(3.27 \%)$ of segmental $\mathrm{IH}$ occurred in the facial beard area or the deep parotid gland, resulting in airway obstruction due to involvement of the pharynx and larynx (Table 2).
Table I Clinical Features of the Nonsegmental IH and Segmental IH Groups

\begin{tabular}{|c|c|c|c|}
\hline Clinical Features & $\begin{array}{l}\text { Nonsegmental } \\
\text { IH }(n=1375)\end{array}$ & $\begin{array}{l}\text { Segmental } \\
\text { IH }(n=\mid 53)\end{array}$ & $P$ value \\
\hline $\begin{array}{l}\text { Sex } \\
\text { Female }\end{array}$ & 958 (69.67\%) & $96(62.75 \%)$ & 0.079 \\
\hline $\begin{array}{l}\text { Age at first } \\
\text { outpatient time } \\
\text { (m) } \\
\text { IH growth stage } \\
\text { Proliferative } \\
\text { Stable } \\
\text { Involuting }\end{array}$ & $\begin{array}{l}3.4 I \pm 2.73 \\
1028(74.76 \%) \\
199(14.47 \%) \\
148(10.76 \%)\end{array}$ & $\begin{array}{l}112(73.20 \%) \\
16(10.46 \%) \\
25(16.34 \%)\end{array}$ & $\begin{array}{l}0.674 \\
0.175 \\
0.039\end{array}$ \\
\hline $\begin{array}{l}\text { IH type } \\
\text { Superficial } \\
\text { Deep } \\
\text { Mixed }\end{array}$ & $\begin{array}{l}1018(74.04 \%) \\
70(5.09 \%) \\
287(20.87 \%)\end{array}$ & $\begin{array}{l}89(58.17 \%) \\
9(5.88 \%) \\
55(35.95 \%)\end{array}$ & $\begin{array}{l}0.000 \\
0.675 \\
0.000\end{array}$ \\
\hline $\begin{array}{l}\text { Location } \\
\text { Head/face } \\
\text { Neck } \\
\text { Limbs } \\
\text { Trunk } \\
\text { Perineal/perianal/ } \\
\text { genital }\end{array}$ & $\begin{array}{l}546(39.71 \%) \\
51(3.71 \%) \\
303(22.04 \%) \\
426(30.98 \%) \\
49(3.56 \%)\end{array}$ & $\begin{array}{l}25(16.34 \%) \\
6(3.92 \%) \\
76(49.67 \%) \\
39(25.49 \%) \\
7(4.58 \%)\end{array}$ & $\begin{array}{l}0.000 \\
0.895 \\
0.000 \\
0.161 \\
0.528\end{array}$ \\
\hline $\begin{array}{l}\text { Date of IH onset } \\
\text { At birth } \\
<15 \mathrm{~d} \\
\geq 15 \mathrm{~d}-<1 \mathrm{~m} \\
\geq 1 \mathrm{~m}-<2 \mathrm{~m} \\
\geq 2 \mathrm{~m}-<3 \mathrm{~m} \\
\geq 3 \mathrm{~m}-<6 \mathrm{~m} \\
\geq 6 \mathrm{~m}\end{array}$ & $\begin{array}{l}371(26.98 \%) \\
494(35.93 \%) \\
222(16.15 \%) \\
190(13.82 \%) \\
67(4.87 \%) \\
24(1.75 \%) \\
7(0.51 \%)\end{array}$ & $\begin{array}{l}69(45.10 \%) \\
56(36.60 \%) \\
13(8.50 \%) \\
10(6.54 \%) \\
2(1.31 \%) \\
2(1.31 \%) \\
1(0.65 \%)\end{array}$ & $\begin{array}{l}0.000 \\
0.869 \\
0.013 \\
0.011 \\
0.044 \\
0.691 \\
0.814\end{array}$ \\
\hline $\begin{array}{l}\text { Complications } \\
\text { Ulceration } \\
\text { Airway } \\
\text { involvement }\end{array}$ & $\begin{array}{l}56(4.07 \%) \\
\text { I (0.07\%) }\end{array}$ & $\begin{array}{l}13(8.50 \%) \\
5(3.27 \%)\end{array}$ & $\begin{array}{l}0.012 \\
0.000\end{array}$ \\
\hline $\begin{array}{l}\text { Risk of } \\
\text { disfigurement } \\
\text { Vision } \\
\text { threatening }\end{array}$ & $\begin{array}{l}289(21.02 \%) \\
7(0.51 \%)\end{array}$ & $\begin{array}{l}20(13.07 \%) \\
I(0.65 \%)\end{array}$ & $\begin{array}{l}0.020 \\
0.814\end{array}$ \\
\hline
\end{tabular}

Abbreviations: IHs, infantile hemangioma; d, day.

\section{Treatments}

After evaluating the situations of the high-risk patients and the treatment requests of the patients' family members at the first visit to our hospital, we determined that more segmental IH patients $(127,83.01 \%)$ required treatment than nonsegmental IH patients. Among the 26 (16.99\%) patients who did not receive treatment, 6 patients were in 

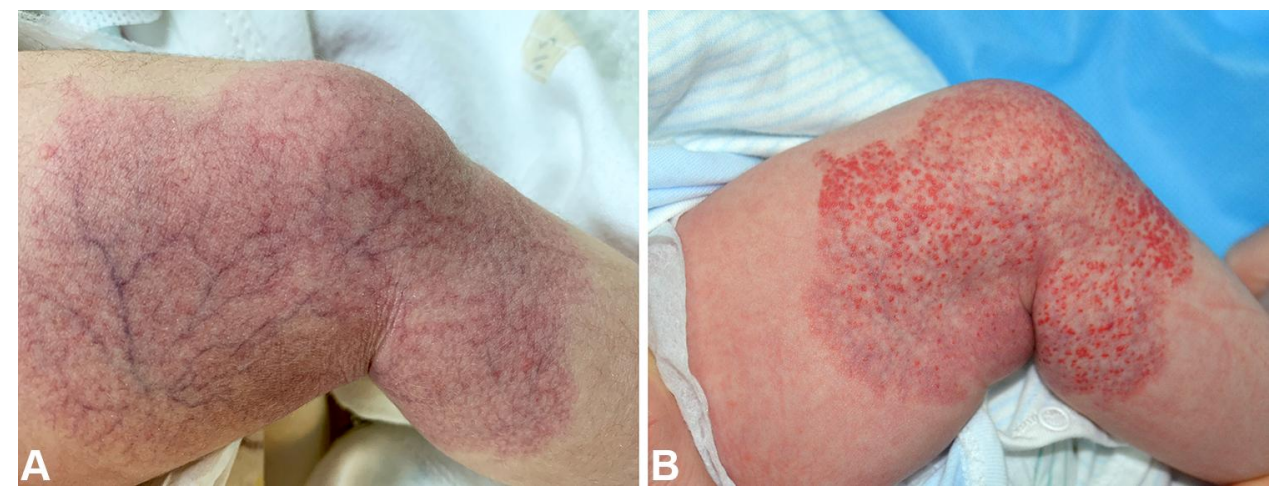

Figure 2 Segmental IH of the right lower limb: It showed a dark red plaque with telangiectasia at birth (A) and a bright red plaque with clustered red papule at the age of 3 weeks (B).

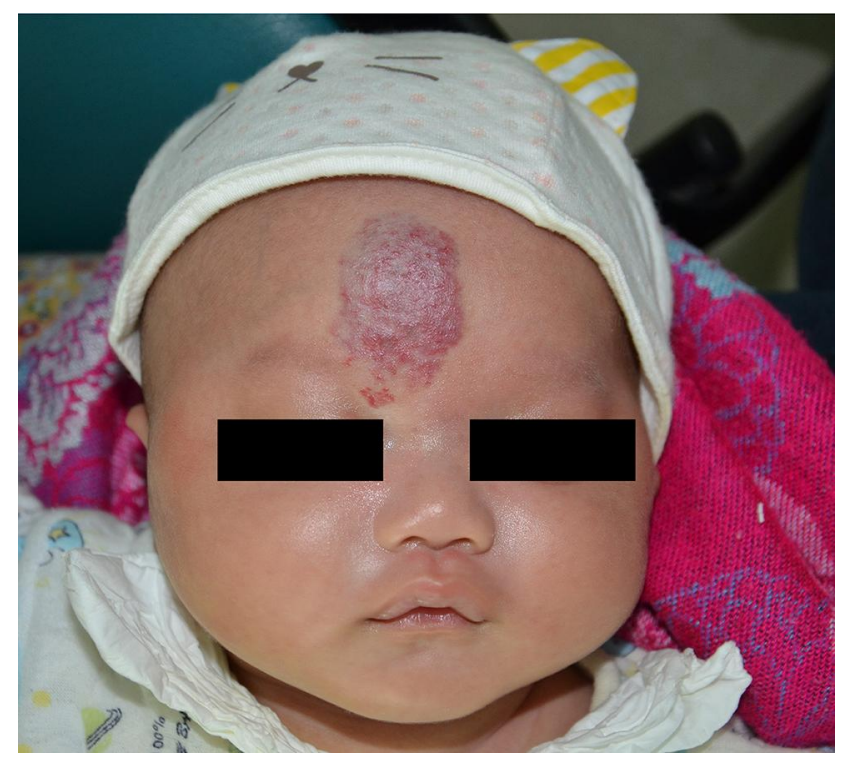

Figure $3 \mathrm{~A}$ four-week-old patient with focal IH was treated with oral propranolol. a stable plateau phase, and 11 patients were in an involuting phase. Seven segmental IHs were located on the extremities. They were superficial and were not associated with serious complications such as ulcers. The other two patients' lesions were located on the right waist and behind the right ear. Their parents refused any treatment. The patients with segmental IHs were more inclined to receive early oral drug interventions than nonsegmental $\mathrm{IH}$ patients $(P<0.001)$. Propranolol at a dose of 2 to $3 \mathrm{mg} / \mathrm{kg}$ per day was administered in 105 (68.63\%) of 153 segmental $\mathrm{IH}$ patients (Table 3 ).

\section{Discussion}

The characteristic growth curves of most IHs are nonlinear. ${ }^{1}$ After a period of 1-3 weeks, an IH begins to proliferate, and the rapid growth period of an $\mathrm{IH}$ is often within the first 3 months of life, ;,6 accordingly, the tumors
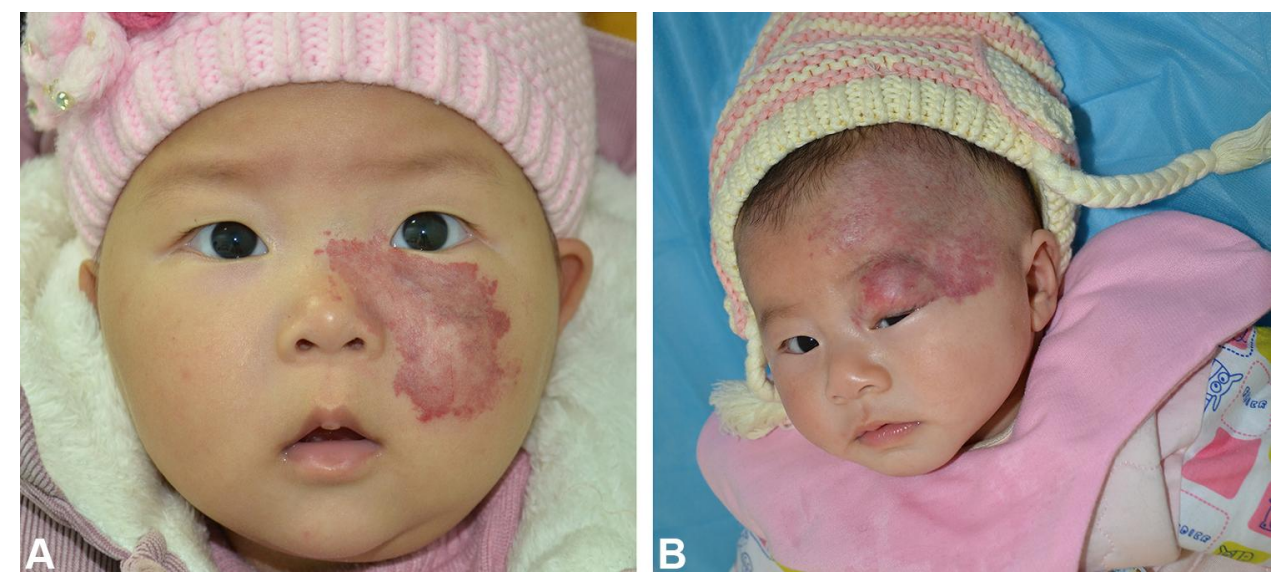

Figure 4 Segmental IH of the face and head: it showed a facial segmental IH with a telangiectatic red macule during involuting stage (A); and a mixed segmental IH with bluish tumor below the red plaque, causing visual field cut. This patient has previously been treated with topical timolol before referral (B). 
Table 2 Distribution of Ulcerated Infantile Hemangioma Locations

\begin{tabular}{|l|l|l|l|}
\hline $\begin{array}{l}\text { Location of } \\
\text { Ulceration }\end{array}$ & $\begin{array}{l}\text { Nonsegmental } \\
\text { IH (n= I375) }\end{array}$ & $\begin{array}{l}\text { Segmental } \\
\text { IH (n= I 53) }\end{array}$ & P value \\
\hline Head/face & $22(1.60 \%)$ & $4(2.61 \%)$ & 0.357 \\
Neck & $2(0.15 \%)$ & $3(1.96 \%)$ & 0.000 \\
Limbs & $12(0.87 \%)$ & $2(1.31 \%)$ & 0.593 \\
Trunk & $9(0.65 \%)$ & $0(0 \%)$ & 0.361 \\
Perineal/ & II $(0.80 \%)$ & $4(2.61 \%)$ & 0.031 \\
perianal/genital & & & \\
\hline
\end{tabular}

may not be noticed until after birth. Because of the large focal areas of segmental IHs and the involvement of one or more anatomical structures, the possibility of detection at birth is greatly increased. However, the precursors of segmental IHs observed at birth may be difficult to distinguish from capillary malformation (CM). ${ }^{7,8}$ Segmental IHs generally initially present as reticular dilated capillaries, while typical IH manifestations such as red plaques or elevated red papule-like IHs gradually appear with increasing age. In addition, some segmental IHs with arrested growth do not show evident proliferation in the postnatal period. Therefore, segmental IHs, which are challenging to identify, need close follow-up and additional observation, with the aim of providing timely intervention and treatment.

Primary care service providers may not be able to evaluate and manage high-risk IHs such as segmental IHs independently. Ideally, the primary care doctors should refer high-risk IH patients to an IH specialist within 4-6 weeks or at least consult an IH specialist for treatment. ${ }^{2}$ As

Table 3 Treatment Differences Between Nonsegmental IH and Segmental IH Groups

\begin{tabular}{|l|l|l|l|}
\hline Characteristics & $\begin{array}{l}\text { Nonsegmental } \\
\text { IH (n= I375) }\end{array}$ & $\begin{array}{l}\text { Segmental } \\
\text { IH (n= 153) }\end{array}$ & P value \\
\hline $\begin{array}{l}\text { Current } \\
\text { treatment } \\
\text { Yes }\end{array}$ & $\begin{array}{l}\text { (n) (60.29\%) } \\
\text { No }\end{array}$ & $\begin{array}{l}127(83.01 \%) \\
26(16.99 \%)\end{array}$ & 0.000 \\
\hline $\begin{array}{l}\text { Current } \\
\text { treatment } \\
\text { therapy }\end{array}$ & $546(39.71 \%)$ & & \\
$\quad \begin{array}{l}\text { Propranolol, } \\
\text { oral }\end{array}$ & $443(32.22 \%)$ & $105(68.63 \%)$ & 0.000 \\
$\quad \begin{array}{l}\text { Timolol, topical } \\
\text { Laser }\end{array}$ & $370(26.91 \%)$ & $9(5.88 \%)$ & 0.000 \\
$\quad$ Surgery & $27(1.96 \%)$ & $18(\mathrm{II} .76 \%)$ & 0.000 \\
\hline
\end{tabular}

Abbreviations: IHs, infantile hemangioma; d, day. a tertiary institution, there was no significant difference in the age at the first outpatient visit or first referral between the segmental IH patients and nonsegmental IH patients. Some patients might not be able to receive timely professional evaluation and treatment or early, frequent and close monitoring. Such delayed referrals greatly delay the evaluation and treatment of patients with high-risk IHs. Some patients may even develop ulcers or serious complications before being referred to a tertiary medical center, so the best time for treatment might be missed, affecting the long-term prognosis of the disease. Therefore, the importance of early identification of segmental IHs and timely referral by primary care doctors is emphasized. The risk assessment and referral timing of no bedridden patients with diseases such as segmental $\mathrm{IH}$ are very important. Telemedicine platforms, ${ }^{9}$ high-quality referral scoring tools, ${ }^{10}$ the score for assessing the response to propranolol treatment ${ }^{11}$ and some other new clinical tools for monitoring $\mathrm{IHs}^{12}$ should be reasonably used to benefit children with IH.

Studies on the clinical characteristics of IH have found that the most common IH sites are the head and face, ${ }^{6,13-16}$ but the "biker-glove" pattern proposed by Weitz NA, ${ }^{17}$ which is a characteristic of segmental IH, was more common in the extremities, coinciding with our conclusion. In our study, nearly half of the segmental IHs occurred in the limbs, while only 25 patients had segmental IHs on the head and face, accounting for $16.34 \%$. The anatomical distribution of segmental IHs was significantly different from that of nonsegmental IHs.

Segmental IH was more often accompanied by complications than nonsegmental IH. Ulceration was one of the most common complications. There was a high incidence of ulcers in IHs on the neck fold area, lip mucous membrane and perineal/perianal/genital area. Especially in the perineal/perianal/genital area, the probability of ulcers was greatly increased due to repeated friction and the presence of bacteria and irritants from urine and feces. ${ }^{4,18}$ When segmental IH occurs in these high-risk ulcer sites, clinical follow-up and daily nursing care by parents, such as changing diapers frequently, reducing friction in the focal area, and so on, should be improved. Ensuring that parents are aware of the risk of ulcers is also important. If ulcers occur, the care of local ulcerated wounds should be strengthened by administering external antimicrobial agents, such as mupirocin ointment, in addition to oral propranolol for $\mathrm{IH}^{19,20}$ Segmental IH located in the beard area often involves the pharynx and larynx, thus greatly increasing the risk of airway obstruction. ${ }^{3,21}$ 
As a high-risk type of $\mathrm{IH}$, segmental $\mathrm{IH}$ has a high possibility of inducing structural abnormalities, such as PHACE syndrome and LUMBAR syndrome. ${ }^{4,8,22}$ In addition, segmental IH may be associated with a higher risk of concomitant hepatic hemangioma than nonsegmental IH. Our ongoing studies involving comorbidity screening in patients with segmental IH could provide additional information in the future.

This study has several limitations. One limitation of the study was that the study population was entirely composed of patients seeking medical evaluation or treatment for $\mathrm{IH}$ at one tertiary medical center. Therefore, our patients might not be representative of the general IH population. Second, information about participants' socioeconomic status was not available. Whether socioeconomic status is associated with the timely referral of patients with $\mathrm{IH}$ is still unknown. Third, our study did not include information about treatment responses and IH involution. Finally, multiple focal lesions received surgical treatment. Perhaps these lesions may spontaneously involute or respond well to propranolol if they had not been resected.

\section{Conclusion}

With the deepening of the understanding of $\mathrm{IH}$, the requirements for the evaluation and management of $\mathrm{IH}$ are becoming increasingly standardized. However, there is little research on high-risk segmental IH. Therefore, it is of great importance for pediatricians, primary care doctors and general practitioners to fully understand the clinical characteristics of segmental $\mathrm{IH}$, properly identify segmental IH, carry out timely referrals and take steps to provide early interventions.

\section{Data Sharing Statement}

Whole data and material needed to support our findings were included in the paper and available for publication.

\section{Ethics Approval and Informed Consent}

Written informed consent was obtained from all the patients' parents according to the provisions of the Declaration of Helsinki.

\section{Consent for Publication}

All the patients or patients' parents signed an informed consent form for the submission to the journal.

\section{Author Contributions}

All authors made a significant contribution to the work reported, whether that is in the conception, study design, execution, acquisition of data, analysis and interpretation, or in all these areas; took part in drafting, revising or critically reviewing the article; gave final approval of the version to be published; have agreed on the journal to which the article has been submitted; and agree to be accountable for all aspects of the work.

\section{Funding}

This work was supported by the National Natural Science Foundation of China (81401606, 81400862), the Key Project in the Science \& Technology Program of Sichuan Province (2019YFS0322), the Science Foundation for The Excellent Youth Scholars of Sichuan University (2015SU04A15), and the 1·3.5 Project for Disciplines of Excellence-Clinical Research Incubation Project of West China Hospital of Sichuan University (2019HXFH056, 2020HXFH048). YJ and SYC as the funders participated in providing the original idea of the work, drafting and revising the manuscript.

\section{Disclosure}

The authors report no conflicts of interest in this work.

\section{References}

1. Léauté-Labrèze C, Harper JI, Hoeger PH. Infantile haemangioma. Lancet. 2017;390:85-94. doi:10.1016/S0140-6736(16)00645-0

2. Krowchuk DP, Frieden IJ, Mancini AJ, et al. Clinical practice guideline for the management of infantile hemangiomas. Pediatrics. 2019;143(1):e20183475. doi:10.1542/peds.2018-3475

3. Orlow SJ, Isakoff MS, Blei F. Increased risk of symptomatic hemangiomas of the airway in association with cutaneous hemangiomas in a "beard" distribution. J Pediatr. 1997;131:643-646. doi:10.1016/ S0022-3476(97)70079-9

4. Calderón-Castrat X, Peceros-Escalante J, Velásquez F, et al. Segmental infantile hemangioma with minimal or arrested growth in LUMBAR syndrome. Actas Dermosifiliogr. 2017;108:475-477. doi:10.1016/j. ad.2016.10.003

5. Tollefson MM, Frieden IJ. Early growth of infantile hemangiomas: what parents' photographs tell us. Pediatrics. 2012;130:e314-20. doi:10.1542/peds.2011-3683

6. Chang LC, Haggstrom AN, Drolet BA, et al. Growth characteristics of infantile hemangiomas: implications for management. Pediatrics. 2008;122:360-367. doi:10.1542/peds.2007-2767

7. Mahady K, Thust S, Berkeley R, et al. Vascular anomalies of the head and neck in children. Quant Imag Med Surg. 2015;5:886-897. doi:10.3978/j.issn.2223-4292.2015.04.06

8. Sazali HB, Allen NM, Murphy A. PHACE syndrome: importance of distinguishing infantile haemangioma from capillary malformation. Arch Dis Child Fetal Neonatal Ed. 2020;105(6):662. doi:10.1136/ archdischild-2020-318923 
9. Frieden IJ, Puttgen KB, Drolet BA, et al. Management of infantile hemangiomas during the COVID pandemic. Pediatr Dermatol. 2020;37:412-418. doi:10.1111/pde.14196

10. Leaute-Labreze C, Baselga Torres E, Weibel L, et al. The infantile hemangioma referral score: a validated tool for physicians. Pediatrics. 2020;145(4):e20191628. doi:10.1542/peds.2019-1628

11. Janmohamed SR, van Oosterhout M, de Laat PC, et al. Scoring the therapeutic effects of oral propranolol for infantile hemangioma: a prospective study comparing the Hemangioma Activity Score (HAS) with the Hemangioma Severity Scale (HSS). J Am Acad Dermatol. 2015;73(2):258-263. doi:10.1016/j.jaad.2015.05.012

12. Tognetti L, Pianigiani E, Ierardi F, et al. A new clinical and dermoscopic monitoring of infantile hemangiomas treated with oral propranolol. Dermatol Ther. 2020:e14283. doi:10.1111/dth.14283

13. Bruckner AL, Frieden IJ. Hemangiomas of infancy. J Am Acad Dermatol. 2003;48:477-93;quiz 94-6. doi:10.1067/mjd.2003.200

14. Haggstrom AN, Drolet BA, Baselga E, et al. Prospective study of infantile hemangiomas: demographic, prenatal, and perinatal characteristics. J Pediatr. 2007;150:291-294. doi:10.1016/j.jpeds.2006.12.003

15. Léauté-Labrèze C, Prey S, Ezzedine K. Infantile haemangioma: part I. Pathophysiology, epidemiology, clinical features, life cycle and associated structural abnormalities. J Eur Acad Dermatol Venereol. 2011;25:1245-1253. doi:10.1111/j.1468-3083.2011.04102.x

16. Munden A, Butschek R, Tom WL, et al. Prospective study of infantile haemangiomas: incidence, clinical characteristics and association with placental anomalies. $B r \quad J$ Dermatol. 2014;170:907-913. doi:10.1111/bjd.12804
17. Weitz NA, Bayer ML, Baselga E, et al. The "biker-glove" pattern of segmental infantile hemangiomas on the hands and feet. $\mathrm{J} \mathrm{Am} \mathrm{Acad}$ Dermatol. 2014;71:542-547. doi:10.1016/j.jaad.2014.04.062

18. Lanoel A, Tosi V, Bocian M, et al. Perianal ulcers on a segmental hemangioma with minimal or arrested growth. Actas Dermosifiliogr. 2012;103:820-823. doi:10.1016/j.ad.2011.07.018

19. Kim HJ, Colombo M, Frieden IJ. Ulcerated hemangiomas: clinical characteristics and response to therapy. $J$ Am Acad Dermatol. 2001;44:962-972. doi:10.1067/mjd.2001.112382

20. Shin HT, Orlow SJ, Chang MW. Ulcerated haemangioma of infancy: a retrospective review of 47 patients. $\mathrm{Br} J$ Dermatol. 2007;156:1050-1052. doi:10.1111/j.1365-2133.2007.07771.x

21. Uthurriague C, Boccara O, Catteau B, et al. Skin patterns associated with upper airway infantile haemangiomas: a retrospective multicentre study. Acta Derm Venereol. 2016;96:963-966. doi:10.2340/ 00015555-2357

22. Rotter A, Samorano LP, Rivitti-Machado MC, et al. PHACE syndrome: clinical manifestations, diagnostic criteria, and management. An Bras Dermatol. 2018;93:405-411. doi:10.1590/abd18064841.20187693
Therapeutics and Clinical Risk Management

\section{Publish your work in this journal}

Therapeutics and Clinical Risk Management is an international, peerreviewed journal of clinical therapeutics and risk management, focusing on concise rapid reporting of clinical studies in all therapeutic areas, outcomes, safety, and programs for the effective, safe, and sustained use of medicines. This journal is indexed on PubMed Central, CAS,
Dovepress

EMBase, Scopus and the Elsevier Bibliographic databases. The manuscript management system is completely online and includes a very quick and fair peer-review system, which is all easy to use. Visit http://www.dovepress.com/testimonials.php to read real quotes from published authors. 